\title{
Predictive value of preschool surveillance in detecting learning difficulties
}

\author{
N Corrigan, M Stewart, $M$ Scott, F Fee
}

\begin{abstract}
Objectives-The Hall report specified the early detection of mild to moderate learning difficulties as one aim of child health surveillance (CHS). This study examines the efficacy of preschool CHS in the early recognition of children with these disorders.
\end{abstract}

Design-A retrospective case-control study.

Subjects-All children ( $n=408)$ with mild to moderate learning difficulties born between 1 July 1983 and 30 June 1984 and resident in North and West Belfast.

Controls-2406 birth records and 150 full child health records controlled for age and geographical area.

Results-The prevalence of mild to moderate learning difficulties in North and West Belfast was $16 \%$. Only $6 \%$ of children with learning difficulties were identified by the CHS in the preschool period, although the detection rate for children eventually requiring placement in schools for moderate learning difficulties was better. Coverage of the CHS ranged from $90 \%$ at the 2 year examination to $98 \%$ at the 4 year examination. Perinatal variables associated with learning difficulties after multiple logistic regression analysis were lower social class (odds ratio (OR) 3.9), prematurity <35 weeks (OR 3.0), male sex (OR 1.6), and birth to an unmarried mother (OR 0.6). Independent preschool variables identified by the CHS were speech delay (OR 3.3), poor parenting skills (OR 4.0), behaviour problems (OR 2.8), enuresis (OR 2.4), poor visual acuity (OR 1.8), and otitis media with effusion (OR 1.4). A statistical model for the early detection of learning difficulties using these risk factors is unable to predict accurately the children who will develop mild to moderate learning difficulties.

Conclusions-The CHS as it existed from 1983 to 1989 in North andWest Belfast was poorly sensitive to the detection of mild to moderate learning difficulties despite excellent coverage. An accurate predictive model for learning difficulties could not be developed from the risk factors documented by the CHS.

(Arch Dis Child 1996;74:517-521)

Dr N Corrigan, Altmagelvin Area Hospital, Londonderry, $\mathrm{N}$ Ireland BT47 1SB.

Accepted 29 December 1995
The Hall report $(1989,1991)$ set out a series of challenges for everyone involved in child health surveillance(CHS). ${ }^{1}$ The aims and objectives of the existing CHS were clarified and a tentative programme for change set out. Hall emphasised the need for careful research and audit of present practice in order to facilitate service development. This paper aims to examine one outcome measure of CHS, the early detection of mild to moderate learning difficulties, and discuss the implications of its findings for current practice.

Historically CHS has always had a strong developmental emphasis. Screening has been aimed at detecting subtle developmental disorders often associated with problems such as mild learning difficulties, speech and language delay, and clumsiness. ${ }^{2}$ The detection of mild to moderate learning difficulties is therefore a valid outcome measure of child health developmental surveillance.

Learning difficulties are a common group of disorders with significant long term morbidity in terms of educational achievement, social interaction, and psychiatric disorders. ${ }^{34}$ Environment can have either positive or negative effects on learning difficulties. ${ }^{56}$ Early detection of learning difficulties and interventions to ameliorate abnormal patterns of learning and secondary behavioural and emotional difficulties have been shown to be beneficial. ${ }^{6-8}$ The efficacy of preschool screening programmes in the early detection of learning difficulties is unclear and there is little information on current CHS practice.

\section{Methods}

North and West Belfast is a deprived inner city area with a population of 180000 . There are 60 mainstream primary schools, two for moderate learning difficulties, and two for severe learning difficulties serving the area. The CHS at the time of the study involved nine mandatory examinations (table 1 ) with varying numbers of follow up visits. Mild to moderate learning difficulties were defined as any child in mainstream education requiring remedial assistance for ability two or more years behind in one or more subjects or any child attending a school for moderate learning difficulties.

The population studied was drawn from all children born between 1 July 1983 and 30 June 1984 with maternal addresses in North and West Belfast. Children were 7 to 8 years old at the time of the study ensuring a minimum of 
Table 1 Timing and content of mandatory examination points for the CHS 1983 - 90

\begin{tabular}{|c|c|c|c|c|c|c|c|c|c|}
\hline & \multicolumn{9}{|c|}{ Time of visit } \\
\hline & First visit & $\begin{array}{l}6 \\
\text { Weeks }\end{array}$ & $\begin{array}{l}6 \\
\text { Months }\end{array}$ & $\begin{array}{l}12 \\
\text { Months }\end{array}$ & $\begin{array}{l}18 \\
\text { Months }\end{array}$ & $\begin{array}{l}2 \\
\text { Years }\end{array}$ & $\begin{array}{l}3 \\
\text { Years }\end{array}$ & $\begin{array}{l}4 \text { Years } \\
\text { preschool }\end{array}$ & $\begin{array}{l}5 \text { Years } \\
R M I\end{array}$ \\
\hline Health worker involved & HV & $\begin{array}{l}\mathrm{HV}+ \\
\text { GP/CMO }\end{array}$ & HV & HV & HV & HV & HV & HV & $\begin{array}{l}\text { HV+ } \\
\text { CMO }\end{array}$ \\
\hline Test & & & MST & MST & MST & & & & \\
\hline
\end{tabular}

CMO = community medical officer; GP = general practitioner; $\mathrm{HV}=$ health visitor; $\mathrm{RMI}=$ routine medical inspection; $\mathrm{MST}=$

Mary Sheridan test.

two years full time primary school education to facilitate detection of significant learning difficulties by their teachers. Children were excluded if the school they attended refused to participate in the study, if they attended a school for severe learning difficulties, or if they were known to have a physical problem likely to contribute to or mimic learning difficulties such as moderate to severe sensorineural deafness, severe visual handicap, etc.

The study group comprised those children attending participating schools and felt by their teachers to meet the study criteria for mild to moderate learning difficulties. The controls were the children attending the same schools, within the same age range, and felt by their teachers not to have significant learning difficulties.

Data from CHS were separated into perinatal data and preschool data. Perinatal data collected are detailed in table 2 . These data were available as computerised records for children in both the study group and controls. Preschool data were obtained by personal review of the written child health record and recorded on a specially designed database. All children with learning difficulties and a $10 \%$ random sample ( 225 children) of the control group had their child health record examined.

The percentage of children identified by CHS as having either developmental delay or learning difficulties within the preschool period formed the principal outcome measure. The diagnosis of developmental delay was accepted where it was either documented in the child health record or where there was evidence of referral to educational psychology or developmental paediatric services for further assessment. The identification and documentation by CHS of known risk factors in either perinatal or preschool surveillance of later learning difficulties were examined as immediate outcomes.

Univariant and multiple logistic regression analysis was used to identify risk factors associated with later learning difficulties. A score based on these risk factors was then calculated for each child. This represented a predictive score for the risk of later mild to moderate learning difficulties. The differences in these scores for the learning difficulties and control groups were examined to establish the sensitivity, specificity, and predictive value of any screening process based on the existing system of CHS. This process was done for the perinatal data and preschool data independently. The databases were then merged to include all children for whom full perinatal and preschool data was available.

\section{Results}

Fifty six (92\%) of the 62 local primary schools agreed to participate in the study, including both schools for children with moderate learning difficulties. There were 2561 children within the correct age range attending these schools. Of these, 21 children were attending primary schools for moderate learning difficulties and 387 were receiving remedial help at mainstream schools giving a total of $408(16 \%)$ children with learning difficulties. Of these 408 children complete perinatal data was available for $380(92 \%)$ and complete preschool data for $355(87 \%)$.

The computerised perinatal records showed 3088 children were born to mothers from North and West Belfast during the study period. Of these, 248 children attended nonparticipating schools, 26 had either severe learning difficulties or other excluding disorders, and 408 had learning difficulties leaving a dataset of some 2406 children in the control group. The extra 253 children were untraceable. Of the 225 controls that also had their child health record reviewed $183(81 \%)$ had full data available. All the children with complete preschool data also had complete perinatal data and formed the cohort for the combined analysis of predictive scores.

Eight per cent of the study group were identified as being at risk of learning difficulties before starting school. Only $75 \%$ of these were directly or indirectly identified through CHS. However $62 \%$ of the children with learning difficulties that warranted placement at a primary school for moderate learning difficulties were identified as at risk of learning difficulties in the preschool period, very significantly more than the children in mainstream primary schools (relative risk=10.3).

The coverage of the mandatory visits ranged from $98 \%$ at first visit to $86 \%$ at 2 years with a

Table 2 Perinatal data collected on each child

\begin{tabular}{lll}
\hline Health visitor & No of previous pregnancies & Delivery mode \\
Sex & No of previous stillbirths & Mother's age \\
Date of birth & No of previous livebirths & Father's age \\
Address & Gestation & Social class \\
No of antenatal visits & Birth weight & Marital status \\
No of weeks worked & Multiplicity & Maternal abnormalities \\
& & Congenital abnormalities
\end{tabular}


Table 3 Percentage coverage of mandatory examination points; values are per cent seen

\begin{tabular}{lllllllll}
\hline \multicolumn{1}{c}{ Time of visit } & & & & & \\
\cline { 2 - 9 } & First & 6 & 6 & 12 & 18 & 2 & 3 & 4 \\
& visit & Weeks & Months & Months & Months & Years & Years & Years \\
\hline Children with learning difficulties & 98 & 95 & 96 & 92 & 95 & 88 & 90 & 96 \\
Controls & 99 & 99 & 97 & 92 & 93 & 83 & 88 & 96 \\
\hline
\end{tabular}

mean of $94 \%$. There was no significant difference in coverage between the control and learning difficulties groups (table 3 ). The mean (SD) number of visits for each child was 17.7 (8.7). Of the 48 different tests employed by the Mary Sheridan screening test only nine were

Table 4 Outcome of Mary Sheridan developmental tests in children with learning difficulties compared with controls

\begin{tabular}{|c|c|c|c|}
\hline Test & $\begin{array}{l}\% \text { Failed in } \\
\text { children } \\
\text { with } \\
\text { learning } \\
\text { difficulties } \\
(n=355)\end{array}$ & $\begin{array}{l}\% \text { Failed in } \\
\text { controls } \\
(n=183)\end{array}$ & pValue \\
\hline \multicolumn{4}{|l|}{ At 6 months } \\
\hline Holds head erect & 0.6 & 0 & 0.43 \\
\hline $\begin{array}{l}\text { Gives arms when } \\
\text { lifted }\end{array}$ & 3.3 & 3.0 & 0.77 \\
\hline Foot regard & 1.5 & 0.5 & 0.32 \\
\hline Rolls & 3.3 & 2.9 & 0.77 \\
\hline $\begin{array}{l}\text { Stops crying when } \\
\text { talked to }\end{array}$ & 0 & 0 & $\mathrm{n} / \mathbf{a}$ \\
\hline Turns head to voices & 0.6 & 0 & 0.4 \\
\hline Brings toys to mouth & 1.2 & 0 & 0.18 \\
\hline $\begin{array}{l}\text { Drinks from cup with } \\
\text { assistance }\end{array}$ & 3.3 & 6.0 & 0.2 \\
\hline Laughs & 0.5 & 0 & 0.43 \\
\hline Babbles & 0.5 & 0 & 0.43 \\
\hline Turns head to sound & 5.0 & 4.0 & 0.56 \\
\hline Four different sounds & 1.8 & 0 & 0.07 \\
\hline Picks up toy & 0.14 & 0 & 0.11 \\
\hline Pulls paper from face & 1.5 & 0.5 & 0.32 \\
\hline Holds two objects & 1.5 & 0 & 0.12 \\
\hline Looks for objects & 1.2 & 0 & 0.18 \\
\hline \multicolumn{4}{|l|}{ At 12 months } \\
\hline Stands aided & 1.9 & 0.5 & 0.23 \\
\hline Crawls & 1.6 & 0.5 & 0.32 \\
\hline Walks aided & 3.7 & 5.0 & 0.43 \\
\hline Stands alone & 8.4 & 7.6 & 0.7 \\
\hline Waves bye bye & 1.5 & 0 & 0.12 \\
\hline Plays pat a cake & 4.6 & 3.8 & 0.6 \\
\hline Helps dress & 1.7 & 2.5 & 0.42 \\
\hline Uses spoon & 2.4 & 3.1 & 0.89 \\
\hline $\begin{array}{l}\text { Two words with } \\
\text { meaning }\end{array}$ & 5.6 & 4.1 & 46 \\
\hline $\begin{array}{l}\text { Follows simple } \\
\text { commands }\end{array}$ & 0.5 & 0 & 0.42 \\
\hline Knows name & 0.3 & 0 & 0.65 \\
\hline $\begin{array}{l}\text { Three words with } \\
\text { meaning }\end{array}$ & 8.7 & 12.6 & 0.2 \\
\hline Pincer grasp & 0.6 & 0 & 0.17 \\
\hline Scribbles & 7.0 & 4.7 & 0.32 \\
\hline Points & 2.8 & 0.5 & 0.08 \\
\hline Hand preference & 6.2 & 5.8 & 0.9 \\
\hline \multicolumn{4}{|l|}{ At 18 months } \\
\hline Climbs small step & 1.0 & 0 & 0.28 \\
\hline Walks pulling object & 1.2 & 0 & 0.18 \\
\hline Walks backwards & 3.2 & 0.5 & 0.06 \\
\hline Climbs stairs & 2.2 & 0 & $\star 0.05$ \\
\hline Uses cup-no mess & 0.6 & 0 & 0.42 \\
\hline Removes own shoes & 0.6 & 2.4 & 0.12 \\
\hline Asks to use toilet & 60.0 & 47.0 & ${ }^{\star} 0.01$ \\
\hline $\begin{array}{l}\text { Bowel control } \\
\text { complete }\end{array}$ & 70.0 & 79.0 & ${ }^{\star} 0.02$ \\
\hline Babbles freely & 2.2 & 0 & ${ }^{\star} 0.05$ \\
\hline Watches pictures & 3.0 & 0 & ${ }^{\star} 0.01$ \\
\hline $\begin{array}{l}\text { Ten words with } \\
\text { meaning }\end{array}$ & 36.0 & 7.6 & $\star 0.0001$ \\
\hline Repeats words & 11.0 & 3.5 & $\star^{\star} 0.004$ \\
\hline $\begin{array}{l}\text { Scribbles } \\
\text { constructively }\end{array}$ & 1.5 & 0 & 0.12 \\
\hline Plays constructively & 5.5 & 0 & $\star 0.002$ \\
\hline $\begin{array}{l}\text { Builds tower of three } \\
\text { bricks }\end{array}$ & 5.0 & 1.2 & ${ }^{\star} 0.04$ \\
\hline Throws ball & 1.2 & 0 & 0.18 \\
\hline
\end{tabular}

significantly discriminatory of later learning difficulties and all of these were at the 18 month test period (table 4).

Univariant analysis showed a number of perinatal and preschool variables were associated with a increased relative risk of later learning difficulties (tables 5 and 6). However after multiple logistic regression analysis only lower social class (odds ratio (OR 3.9), prematurity $<35$ weeks (OR 3.0), male sex (OR 1.6), and birth to an unmarried mother (OR 0.6) in the perinatal dataset and speech delay (OR 3.3), poor parenting skills (OR 4.0), behaviour problems (OR 2.8), enuresis (OR 2.4), poor visual acuity (OR 1.8), and otitis media with effusion (OR 1.4) in the preschool period were associated with learning difficulties (table 7). In the preschool period $23 \%$ of children who went on to develop learning difficulties had no significant risk factors documented in their child health record.

Figure 1 shows the spread of predictive values using a combined perinatal and preschool variable model. In order to identify $85 \%$ of the children at risk using this model one would have to screen $62 \%$ of the total population.

\section{Discussion}

Recent changes within the National Health Service have placed increasing emphasis on developing outcome measures that can be used to evaluate clinical practice. In particular the implementation of screening programmes such as CHS with large resource implications should be based on sound scientific research.

Learning difficulties are a common condition ${ }^{910}$ with significant morbidity ${ }^{34}$ and proved efficacious intervention ${ }^{78}$ and thus fulfil three basic criteria for screening. What remains to be established is the validity of the tests currently used in the detection of children with learning difficulties in the preschool period. The good case ascertainment rates, well defined geographically limited population,

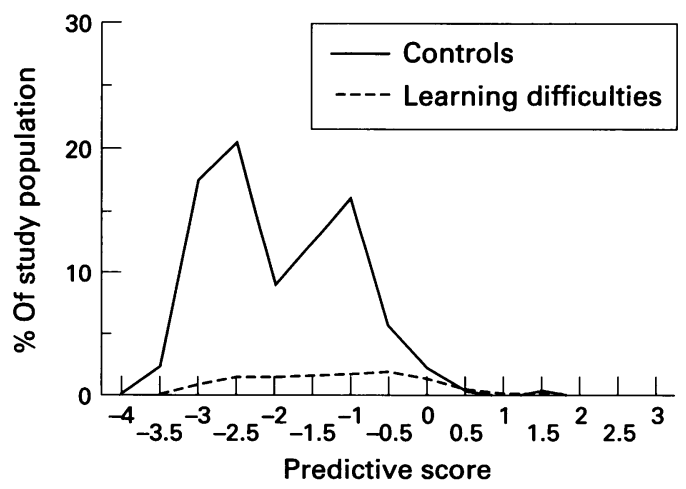

Figure 1 Spread of predictive scores between children with learning difficulties and controls. 
Table 5 Perinatal risk factors associated with later learning difficulties

\begin{tabular}{lllll}
\hline Risk factor & $\begin{array}{l}\text { \% Children with } \\
\text { learning difficulties } \\
(n=380)\end{array}$ & $\begin{array}{l}\text { \% Controls } \\
(n=2406)\end{array}$ & OR & $\begin{array}{l}\text { 95\% Confidence } \\
\text { interval }\end{array}$ \\
\hline Lower social class (social class V or less) & $254(67)$ & $950(39)$ & 3.1 & 2.5 to 3.9 \\
Prematurity ( 35 weeks) & $25(7)$ & $51(2)$ & 3.2 & 2.0 to 5.1 \\
Multiple birth & $12(3)$ & $40(1.6)$ & 1.9 & 1.0 to 3.7 \\
Low birth weight ( $2500 \mathrm{~g})$ & $39(10)$ & $148(6)$ & 1.7 & 1.2 to 2.5 \\
Male sex & $233(61)$ & $1194(50)$ & 1.6 & 1.3 to 2.0 \\
Unmarried mother & $90(24)$ & $449(19)$ & 1.3 & 1.0 to 1.7 \\
Assisted delivery & $87(23)$ & $541(22)$ & 1.0 & 0.8 to 1.3 \\
\hline
\end{tabular}

Table 6 Prevalence of documented problems in children with learning difficulties compared with controls

\begin{tabular}{|c|c|c|c|c|}
\hline Problem documented & $\begin{array}{l}\text { Total \% with problem in } \\
\text { children with learning } \\
\text { difficulties }(n=355)\end{array}$ & $\begin{array}{l}\text { Total \% with problem in } \\
\text { controls }(n=183)\end{array}$ & pValue & $\begin{array}{l}\text { OR ( } 95 \% \text { confidence } \\
\text { interval) }\end{array}$ \\
\hline \multicolumn{5}{|l|}{ Developmental } \\
\hline Speech delay & 46 & 18 & 0.0001 & $3.8(2.4$ to 6.0$)$ \\
\hline Behavioural problems & 9 & 3 & 0.01 & $3.6(1.3$ to 10.8$)$ \\
\hline Global delay & 5 & 0 & 0.01 & Undefined \\
\hline Poor gait & 4 & 3 & 0.6 & \\
\hline Poor feeding & 5 & 3 & 0.3 & \\
\hline Poor concentration & 6 & 1 & 0.01 & $5.1(1.2$ to 45.4$)$ \\
\hline Gross motor delay & 3 & 2 & 0.4 & \\
\hline \multicolumn{5}{|l|}{ Hyperactivity } \\
\hline Clumsy & 3 & 1 & 0.09 & $3.2(0.7$ to 29.4$)$ \\
\hline Hypotonia & 1 & 1 & 0.7 & \\
\hline Fine motor delay & 1 & 0 & 0.1 & Undefined \\
\hline \multicolumn{5}{|l|}{ Hearing } \\
\hline OME +/- vents & 25 & 18 & 0.08 & $1.5(0.9$ to 2.3$)$ \\
\hline Failed hearing test & 4 & 3 & 0.8 & \\
\hline Adenoidal hypertrophy & 1 & 1 & 0.3 & \\
\hline \multicolumn{5}{|l|}{ Medical } \\
\hline Enuresis & 8 & 3 & 0.03 & $2.6(1.0$ to 7.8$)$ \\
\hline Asthma & 5 & 7 & 0.4 & \\
\hline Cardiac murmur & 5 & 2 & 0.08 & $2.5(0.8$ to 10.4$)$ \\
\hline Eczema & 2 & 3 & 0.6 & \\
\hline Febrile seizures & 3 & 1 & 0.2 & \\
\hline Non-febrile seizures & 1 & 1 & 0.5 & \\
\hline Constipation & 1 & 0 & 0.4 & \\
\hline Oesophageal reflex & 1 & 1 & 0.5 & \\
\hline Inguinal hernia & 2 & 0 & 0.03 & Undefined \\
\hline Undescended testes & 1 & 1 & 0.9 & \\
\hline \multicolumn{5}{|l|}{ Environmental } \\
\hline Poor housing & 14 & 5 & 0.01 & $2.7(1.3$ to 6.0$)$ \\
\hline Poor parenting & 9 & 2 & 0.001 & $6.2(1.9$ to 31.6$)$ \\
\hline Maternal depression & 3 & 2 & 0.2 & \\
\hline Poor home environs & 4 & 1 & 0.08 & $3.4(0.8$ to 31.6$)$ \\
\hline Abuse & 3 & 1 & 0.1 & 4.7 (0.6 to 208$)$ \\
\hline Alcohol abuse (parent) & 2 & 0 & 0.08 & Undefined \\
\hline Financial problems & 2 & 1 & 0.2 & \\
\hline \multicolumn{5}{|l|}{ Vision } \\
\hline Poor visual acuity & 16 & 9 & 0.01 & $2.0(1.1$ to 3.8$)$ \\
\hline Squint & 8 & 6 & 0.6 & \\
\hline \multicolumn{5}{|l|}{ Growth } \\
\hline Small stature & 8 & 5 & 0.2 & \\
\hline Failure to thrive & 3 & 2 & 0.2 & \\
\hline Microcephaly & 1 & 1 & 0.9 & \\
\hline Obesity & 1 & 1 & 0.5 & \\
\hline
\end{tabular}

$\mathrm{OME}=$ otitis media with effusion.

and the high participation of local schools minimised bias by educational provision, social class, environmental pressures, or different ethnic mixes.

The 253 children on the perinatal database that were not accountable for had presumably either left the area or died. If we accept $16 \%$ of these as having learning difficulties, this would represent a $1 \%$ contamination of the 2406 controls with false negatives that would be statistically acceptable and unlikely to effect the results.

In this study CHS examinations failed to detect the majority of children with mild learning difficulties and missed $38 \%$ of children with moderate learning difficulties. The improved detection rate for the children at schools for moderate learning difficulties may be related to the more severe nature of their learning difficulties. However early detection itself may make appropriate placement more likely, whereas late detection may delay placement in a suitable environment. Retrospective analysis of the child health record also failed to identify a model that would predict children at risk of later learning difficulties. These findings have implications for the future development of CHS.

Why children with learning difficulties were not detected was also examined. Possible reasons include inadequate or inappropriate timing of examinations, poor application of the screening tests, or the use of inappropriate screening tests. The natural progression of the condition may also be such that early detection is not possible.

The failure of CHS is unlikely to be due to timing of examinations as each child had nine 
mandatory visits and an average of nine follow up visits in the preschool period, considerably more than recommended today. ${ }^{1}$

There is a wide choice of developmental screening tests available that vary in clinical accuracy. ${ }^{11}$ The validity of a test in predicting school performance can vary and teacher assessment can be just as accurate. ${ }^{12}{ }^{13}$ The 'pass/fail' style of developmental assessment used in this study is more structured than those presently recommended, ${ }^{1}$ which are based more on clinical judgment. However as results based on clinical judgment been shown to correlate well with pass/fail testing ${ }^{14} 15$ it is unlikely that this difference is responsible for the failure of CHS.

It is unlikely that the tests were poorly applied. All health visitors were fully trained in the developmental techniques employed. The excellent coverage indicates a dedicated and motivated workforce, despite the recognised difficulties of working in an inner city area. ${ }^{16}$ In addition the high prevalence of documented speech delay suggests that at least parts of the tests were applied correctly. ${ }^{11}$

The natural history of learning difficulties overlaps with normal developmental making early detection difficult. Previous studies have established the predictive value of certain parental, perinatal, and preschool variables in detecting learning difficulties. ${ }^{17}$ Many of these used test conditions or included variables that would be difficult to apply to a nationwide screening programme because of implications for training or resources. Our study differed in that it examined the screening programme currently in place for all children. We found that although certain variables were significantly more common in children with learning difficulties, they could not be used to construct an accurate predictive model for later learning difficulties. The majority of risk factors documented (tables 4-7) are well recognised associations of learning difficulties.

We contend that the failure of CHS was due to a combination of poor test sensitivity and the wide overlap of learning difficulties with variants of normal development.

Table 7 Risk factors associated with learning difficulties after multiple logistic regression analysis

\begin{tabular}{lll}
\hline Risk factor & OR & $\begin{array}{l}\text { 95\% } \\
\text { Confidence } \\
\text { interval }\end{array}$ \\
\hline Perinatal & & \\
$\quad$ Lower social class (IV - VII) & 3.9 & 3.0 to 4.9 \\
Prematurity & 3.0 & 1.4 to 5.1 \\
Male sex & 1.6 & 1.3 to 2.1 \\
$\quad$ Unmarried mother & 0.6 & 0.4 to 0.8 \\
Preschool & 3.3 & 2.1 to 5.2 \\
$\quad$ Speech delay & 4.0 & 1.1 to 14.0 \\
Poor parenting skills & 2.8 & 1.0 to 7.6 \\
Behavioural problems & 2.4 & 0.9 to 4.1 \\
$\quad$ Enuresis & 1.8 & 1.0 to 3.3 \\
Poor visual acuity & 1.4 & 0.9 to 2.3 \\
$\quad$ Otitis media with effusion & & \\
\hline
\end{tabular}

\section{Conclusions}

The CHS did not meet its stated aim of early detection of children with learning difficulties. Our study would suggest that shortcomings in coverage, timing of the visits, or application of the screening tests used are unlikely to be major contributors to this failure. It is more likely that the tests employed were not sensitive enough to differentiate between minor developmental problems in children with learning difficulties and variants of 'normal' development. The value of early detection and intervention for children with learning difficulties is established. More studies are required to determine if other screening tests can meet the requirements of efficacy and time restraints that would allow earlier detection of these at risk children. Exploration of other options for surveillance such as mandatory nursery school placement combined with increased parental and professional awareness may provide a more accurate method of recognising children with significant developmental delay and targeting already stretched resources.

1 Hall DMB. Health for all children. 2nd Ed. Oxford: Oxford University Press, 1991.

2 Dworkin PH. Developmental screening-expecting the impossible? Pediatrics 1989; 83: 619-22.

3 Rutter M, Madge N. Cycles of disadvantage. London: Heinemann, 1976: 46-65.

4 Kohlberg L, LaCross J, Ricks D. The predictability of adult mental health from childhood behaviour. In: Wolman B, ed. Manual of child psychopathology. Toronto: McGraw, 1972: 1233-42.

5 Hagberg B, Hagberg G, Lewerth A, Lindberg U. Mild mental retardation in Swedish school children 1. Prevalence. Acta Paediatr Scand 1981; 70: 441-4.

6 Weisglas-Kuperus N, Baerts W, Smrkovsly M, Sauer PJ. Effects of biological and social factors on the cognitive Effects of biological and social factors on the cognitive 1993; 92: 658-65.

7 Brooks-Gunn J, Klebanov PK, Liaw F, Spiker D. Enhancing the development of low-birthweight premature infants: changes in cognition and behaviour over the first three years. Child Dev 1993; 64: 736-53.

8 Achenbach TM, Howell CT, Aoki MF, Rauh VA. Nine-year outcome of the Vermont intervention programme for low birth weight infants. Pediatrics 1993; 91: 45-55.

9 Nader PR, Ray L, Brink S. The new morbidity: use of school and community health care resources for behavoiural, educational and social-family problems. Pediatrics 1981; 67: $53-60$.

10 Cadman D, Boyle M, Szatmari P, et al. Chronic illness, disabilities, mental and social well being: findings of the abilities, mental and social well being: findings of
Ontario child health study. Pediatrics $1987 ; 79: 812-7$.

11 Glasgoe FP, Martin ED, Humphry S. A comparative review of developmental screening tests. Pediatrics 1990; 86: 54754.

12 Meisels SJ. Can developmental screening tests identify children who are developmentally at risk? Pediatrics 1989; 83: 578-85.

13 Cadman D, Walter SD, Chambers LW, et al. Predicting problems in school performance from preschool health, developmental and behavioural assessments. Can Med Assoc $\mathcal{F}$ 1988; 139: 31-6.

14 Glasgoe FP, Altemeier WA, MacLean WE. The importance of parents concerns about their child's development. $A m \mathcal{F}$ Dis Child 1988; 143: 955-8.

15 Glasgoe FP. Can clinical judgement detect children with speech-language problems? Pediatrics $1991 ; 87 ; 317-22$.

16 Rona RJ, Allsop M, Morris RW. Monitoring the developmental examination schedule in an inner city health district. Child Care Health Dev 1987; 13: 329-40.

17 Seigle LS. Biological and environmental variables a predictors of intellectual functioning at 6 years of age. The at risk infant: psycho/social/medical aspects. Paul Brookes, 1985:6573.

18 Kochanek TL, Kabacoff RI, Lipsitt LP. Early identification of developmentally disabled and at risk preschool children. Exceptional Children 1990; 56: 528-38. 